\title{
Psoralen accelerates osteogenic differentiation of human bone marrow mesenchymal stem cells by activating the TGF- $\beta /$ Smad3 pathway
}

\author{
YONGQUAN HUANG ${ }^{1,2}$, LIU LIAO $^{2}$, HAITAO SU ${ }^{1}$, XINLIN CHEN ${ }^{3}$, TAO JIANG ${ }^{1}$, JUN LIU ${ }^{1}$ and QIUKE HOU ${ }^{4}$ \\ ${ }^{1}$ Department of Orthopaedics, The Second Affiliated Hospital of Guangzhou University of Chinese Medicine, \\ Guangzhou, Guangdong 510006; ${ }^{2}$ Graduate School and ${ }^{3}$ Department of Preventive Medicine and Health Statistics, \\ Guangzhou University of Chinese Medicine; ${ }^{4}$ Department of Gastroenterology, The First Affiliated Hospital of \\ Guangzhou University of Chinese Medicine, Guangzhou, Guangdong 510405, P.R. China
}

Received December 30, 2020; Accepted May 7, 2021

DOI: $10.3892 /$ etm.2021.10372

\begin{abstract}
Psoralen, one of the active ingredients in Psoralea corylifolia, has been previously reported to regulate the osteogenic differentiation of bone marrow mesenchymal stem cells (BMSCs). A previous study revealed that psoralen can regulate the expression levels of microRNA-488 and runt-related transcription factor $2(\operatorname{Runx} 2)$ to promote the osteogenic differentiation of BMSCs. However, the underlying signalling pathway in this process remains to be fully elucidated. BMSCs have also been confirmed to play a key role in the occurrence and development of osteoporosis, and are expected to be potential seed cells in the treatment of osteoporosis. In order to explore the potential signalling pathways of psoralen acting on BMSCs, in the present study, human BMSCs (hBMSCs) were treated with different concentrations of psoralen $(0.1,1$, 10 and $100 \mu \mathrm{mol} / \mathrm{l}$ ) and the TGF- $\beta$ receptor I (RI) inhibitor SB431542 $(5 \mu \mathrm{mol} / \mathrm{l})$ in vitro for 3,7 or 14 days. Cell Counting Kit- 8 and MTT assays were used to measure cell proliferation and cell viability of hBMSCs following psoralen administration. Alkaline phosphatase (ALP) activity and alizarin red $\mathrm{S}$ staining were used to assess the osteogenic differentiation ability of hBMSCs. Reverse transcription-quantitative PCR and western blotting were used to measure the expression of
\end{abstract}

Correspondence to: Professor Qiuke Hou, Department of Gastroenterology, The First Affiliated Hospital of Guangzhou University of Chinese Medicine, 12 Jichang Road, Guangzhou, Guangdong 510405, P.R. China

E-mail: houqiuke@gzucm.edu.cn

Professor Jun Liu, Department of Orthopaedics, The Second Affiliated Hospital of Guangzhou University of Chinese Medicine, 55 Inner Ring West Road, Guangzhou, Guangdong 510006, P.R. China

E-mail: liujun_tcm@163.com

Key words: psoralen, bone marrow mesenchymal stem cells, osteogenic differentiation, TGF- $\beta / \mathrm{Smad} 3$ osteogenic differentiation-related genes [bone morphogenetic protein 4 (BMP4), osteopontin (OPN), Runx2 and Osterix] and proteins associated with the TGF- $\beta / \mathrm{Smad} 3$ pathway [TGF- $\beta 1$, TGF- $\beta$ RI, phosphorylated (p-)Smad and Smad3]. Psoralen was found to increase the proliferation and viability of hBMSCs. Although different concentrations of psoralen enhanced ALP activity and the calcified nodule content in hBMSCs, the enhancement effects were more potent at lower concentrations $(0.1,1$ and $10 \mu \mathrm{mol} / \mathrm{l})$. The expression of BMP4, OPN, Osterix, Runx2, TGF- $\beta 1$, TGF- $\beta$ RI and p-Smad3 was also promoted by psoralen at lower concentrations $(0.1,1$ and $10 \mu \mathrm{mol} / \mathrm{l})$. In addition, whilst SB431542 could inhibit calcium deposition and osteogenic differentiation-related gene expression in hBMSCs, psoralen effectively reversed the inhibitory effects of SB431542. In conclusion, psoralen accelerates the osteogenic differentiation of hBMSCs by activating the TGF- $\beta / \mathrm{Smad} 3$ pathway, which may be valuable for the future clinical treatment of osteoporosis.

\section{Introduction}

Osteoporosis is a common systemic skeletal bone disease that is mainly caused by age-related bone loss (1). For the treatment of osteoporosis, inhibition of bone resorption is an important strategy to enhance bone mineral density to slow the deterioration of the condition (2). However, the toxicity and side effects of a number of agents remain to be problematic. Although bisphosphonates confer clear analgesic effects, improve bone density and decrease the risk of fracture, they are associated with gastrointestinal reactions (2). In addition, teriparatide can increase the activity of osteoblasts, but is expensive and therefore yields poor patient compliance (2). At present, it is difficult to achieve satisfactory clinical outcomes following the treatment of osteoporosis (3). A novel strategy of promoting the differentiation of osteoblasts or the regeneration of bone tissues to slow the development of osteoporosis has been previously proposed by using bone marrow mesenchymal stem cells (BMSCs) (4,5). Mesenchymal stem cells are pluripotent stem cells derived from the mesoderm and are widely distributed in tissues, including adipose tissues, 
periosteum and bone marrow (6). It has been previously reported that BMSCs can continuously promote the formation of new fibroblasts and bone, thereby serving a potentially beneficial role in the reconstruction of bone (6). Therefore, BMSCs are currently the subject of extensive osteoporosis research due to their diverse source as they are easily extracted from bone marrow, lack of immune rejection (7) and have no ethical issues when compared with embryonic stem cells (8).

As understanding on the pathophysiology of osteoporosis deepens in the field of Traditional Chinese Medicine (TCM), psoralen has been reported to exert an effect on the osteogenic differentiation of BMSCs (9). Psoralen occurs naturally in the seeds of the Psoralea corylifolia herb, which has been extensively applied for the clinical treatment of fractures, bone defects and osteoporosis as a herbal TCM (10). Mechanistically, a previous study revealed that psoralen can promote the differentiation of BMSCs into osteoblasts (11). Li et al (12) treated hFOB1.19 cells with different concentrations $(0,5$, 10,15 and $20 \mu \mathrm{M}$ ) of psoralen and found that psoralen stimulated the proliferation of hFOB1.19 cells in a dose-dependent manner. The results demonstrated that the exact mechanism may be related to the activation of the $N F-\kappa B$ signalling pathway (12). In addition, Tang et al (13) stimulated primary mouse calvarial osteoblasts with different doses of psoralen and found that psoralen promoted their differentiation into osteoblasts in a dose-dependent manner (13). Psoralen upregulated the expression of Bmp2 and Bmp 4 genes, and activated the BMP reporter gene (12xSBE-OC-Luc) (13). This indicates that the promotion of osteoblast differentiation by psoralen may be related to BMP signalling (13). Despite the findings of previous studies, the exact underlying molecular mechanism and signalling pathway mediating this process remain to be fully elucidated.

Therefore, the present study explores the effect of varying concentrations of psoralen on the osteogenic differentiation of human BMSCs (hBMSCs) and investigates the association between psoralen and the TGF- $\beta / \mathrm{Smad} 3$ pathway, with aims of providing a reference for the development of treatment strategies for osteoporosis.

\section{Materials and methods}

Cell culture. hBMSCs (cat. no. BNCC338194) were obtained from BeNa Culture Collection. hBMSCs were cultured in DMEM (Thermo Fisher Scientific, Inc.) with $100 \mathrm{mg} / \mathrm{ml}$ streptomycin and $100 \mathrm{U} / \mathrm{ml}$ penicillin (Wuhan Boster Biological Technology, Ltd.) and 10\% FBS (Sigma-Aldrich; Merck $\mathrm{KGaA}$ ). The cells were grown in an incubator at $37^{\circ} \mathrm{C}$ and $5 \% \mathrm{CO}_{2}$. The medium was replaced every 3 days. The cells were digested using $0.05 \%$ EDTA and $0.25 \%$ trypsin (Sigma Aldrich; Merck KGaA) and passaged when they filled $~ 80 \%$ of the culture flask. hBMSCs at passage three were used in the present study.

Treatment of cells. The hBMSCs were seeded into a 96-well plate at a density of $1 \times 10^{4}$ cells/well and cultured in complete medium. After $24 \mathrm{~h}$ the complete medium was replaced with serum-free medium and psoralen (purity $>99 \%$; cat. no. 110739-201416; China Food and Drug Administration) was added and dissolved in DMSO. The concentrations used were
$0.1,1,10$ and $100 \mu \mathrm{mol} / \mathrm{l}$, with each concentration added to 6 replicate wells per experimental repeat. The $0 \mu \mathrm{mol} / 1$ psoralen condition was used as the negative control (NC) group. When SB431542 was required, $5 \mu \mathrm{mol}$ of SB431542 and different concentrations of psoralen $(0.1,1,10$ and $100 \mu \mathrm{mol} / \mathrm{l})$ were administered at the same time and co-cultured with hBMSCs at $37^{\circ} \mathrm{C}$ for 3,7 or 14 days.

Cell Counting Kit-8 (CCK-8) assay of cell proliferation. Third-passage hBMSCs were collected and seeded into 96-well plates at a density of $1 \times 10^{4}$ cells/well and co-cultured with different concentrations $(0.1,1,10$ and $100 \mu \mathrm{mol} / \mathrm{l})$ of psoralen. Following cell culture for 12, 24, 36, 48 and $72 \mathrm{~h}$ at $37^{\circ} \mathrm{C}, 10 \mu \mathrm{l}$ CCK-8 solution (Dojindo Molecular Technologies, Inc.) was added into each well. Cells were then incubated in the dark at $37^{\circ} \mathrm{C}$ for $2 \mathrm{~h}$. Absorbance values were detected at a wavelength of $450 \mathrm{~nm}$ using a microplate reader (Bio-Rad Laboratories, Inc.). hBMSCs cultured with $0 \mu \mathrm{mol} / 1$ psoralen were used as a NC group. A total of 6 replicate wells were established for each group before the average values were calculated.

Cell viability analysis. Third-passage hBMSCs were seeded into 96 -well plates at $1 \times 10^{4}$ cells/well. Following cell adherence to the culture flask, the original medium (DMEM containing $10 \%$ FBS) was discarded and replaced with serum-free medium. Following $24 \mathrm{~h}$ of incubation at $37^{\circ} \mathrm{C}$, hBMSCs were co-cultured with psoralen $(0.1,1,10$ and $100 \mu \mathrm{mol} / \mathrm{l})$ for 24,48 and $72 \mathrm{~h}$ at $37^{\circ} \mathrm{C}$. A total of $20 \mu \mathrm{l} 5 \mathrm{~g} / 1 \mathrm{MTT}$ was added to each well and cells were incubated at $37^{\circ} \mathrm{C}$ for $4 \mathrm{~h}$. Subsequently, the medium was discarded, $150 \mu \mathrm{l}$ of DMSO was added before shaking for $10 \mathrm{~min}$ and absorbance was measured using a microplate reader at $570 \mathrm{~nm}$. A total of 6 replicate wells were established for each group and the average values were calculated.

Alkaline phosphatase (ALP) activity analysis. Third-passage hBMSCs were seeded into 48-well plates. Following cell adherence to the culture flask, the DMEM was discarded and hBMSCs were incubated with different concentrations $(0.1$, $1,10$ and $100 \mu \mathrm{mol} / \mathrm{l})$ of psoralen and osteogenic differentiation medium (cat. no. RASMX-90021; Cyagen Biosciences, Inc.) for 7 days at $37^{\circ} \mathrm{C}$. An osteogenic differentiation inducer without any treatment was used as a NC group. The medium was changed every 2 days. Subsequently, the cells were rinsed three times with PBS and treated with $150 \mu 1$ $0.05 \%$ Triton X-100 for $10 \mathrm{~min}$ at room temperature. An ALP kit (cat. no. AP0100; Sigma-Aldrich; Merck KGaA) was used to detect the ALP activity of hBMSCs according to the manufacturer's instructions. The wavelength was set to $520 \mathrm{~nm}$ and a total of 6 replicate wells were established in each group. The average value was calculated.

Calcium deposition detection. The Alizarin Red staining method (AR-S) for calcium nodules was used to evaluate the extent of bone formation in hBMSCs. Third-passage hBMSCs were inoculated into a 6-well plate with different concentrations of psoralen $(0.1,1,10$ and $100 \mu \mathrm{mol} / \mathrm{l})$ and osteogenic differentiation medium. Six replicate wells were established for each concentration. An osteogenic differentiation inducer 
without any treatment was used as a NC group. The medium was replaced every 2-3 days for 2 weeks at $37^{\circ} \mathrm{C}$. The cells were fixed with $4 \%$ formaldehyde for $15 \mathrm{~min}$ at room temperature, adjusted to $\mathrm{pH} 4.2$ and stained with $0.1 \%$ Alizarin Red (Sigma-Aldrich; Merck KGaA). Cells were incubated overnight at room temperature and subsequently washed three times with PBS. Stained cells were photographed using a digital camera (Nikon Corporation) under a light microscope (magnification, $\mathrm{x} 100)$. In order to detect calcium deposits, cells were then treated with $10 \%$ cetylpyridinium chloride (Sigma-Aldrich; Merck KGaA) in $10 \mathrm{mM}$ sodium phosphate for $15 \mathrm{~min}$ at room temperature. A multifunctional microplate reader (Varioskan LUX; Thermo Fisher Scientific, Inc.) was used to measure the absorbance value at $560 \mathrm{~nm}$ in each well. The experiment was repeated three times and the average value was taken.

Reverse transcription quantitative $(R T-q) P C R$. Third-passage hBMSCs were inoculated into a 6-well plate and co-cultured with osteogenic differentiation medium and different concentrations of psoralen $(0.1,1,10$ and $100 \mu \mathrm{mol} / \mathrm{l})$ or $5 \mu \mathrm{mol} \mathrm{SB} 431542$ (cat. no. SF7890; Beyotime Institute of Biotechnology) for $72 \mathrm{~h}$ at $37^{\circ} \mathrm{C}$. Following $72 \mathrm{~h}$ of co-cultivation of hBMSCs with different concentrations of psoralen or SB431542, RT-qPCR was used to detect the expression of osteogenic differentiation-related genes of hBMSCs. Total RNA from the hBMSCs was extracted using TRIzol ${ }^{\circledR}$ reagent (Thermo Fisher Scientific, Inc.). NanoDrop2000 was used to measure RNA concentration and purity. PrimeScript ${ }^{\mathrm{TM}}$ RT Master Mix (cat. no. RR036A; Takara Bio, Inc.) was used for reverse transcription according to the manufacturer's instructions. The following protocol was used: $37^{\circ} \mathrm{C}$ for $15 \mathrm{~min}$ (reverse transcription reaction) and $85^{\circ} \mathrm{C}$ for $5 \mathrm{sec}$ (reverse transcriptase inactivation reaction). The cDNA obtained by reverse transcription was amplified on StepOne Plus (Thermo Fisher Scientific, Inc.) using the SYBR ${ }^{\mathrm{TM}}$ Green PCR Premix kit (Thermo Fisher Scientific, Inc.) according to the manufacturer's protocol. The thermocycling conditions used were as follows: $50^{\circ} \mathrm{C}$ for $2 \mathrm{~min}$ and $95^{\circ} \mathrm{C}$ for $10 \mathrm{~min}$; followed by $95^{\circ} \mathrm{C}$ for $15 \mathrm{sec}$ and $60^{\circ} \mathrm{C}$ for $60 \mathrm{sec}$ for 40 cycles; and final extension at $72^{\circ} \mathrm{C}$ for $1 \mathrm{~min}$. Relative mRNA levels were quantified using the $2^{-\Delta \Delta \mathrm{Cq}}$ method (14). The $\Delta \mathrm{Cqs}$ values were obtained from $\mathrm{Cq}$ normalized to that of GAPDH. The primers were synthesized by Sangon Biotech Co., Ltd. and are displayed in Table I. The experiment was repeated three times and the average value was calculated.

Western blot (WB) analysis. After 7 days of treatment with different concentrations of psoralen or $5 \mu \mathrm{mol}$ of SB431542, hBMSCs were lysed with RIPA buffer (cat. no. P0013B; Beyotime Institute of Biotechnology) containing protease and phosphatase inhibitors, and centrifuged at $14,000 \times \mathrm{g}$ at $4^{\circ} \mathrm{C}$ for $20 \mathrm{~min}$. The supernatant was the total protein and was used to determine the protein concentration using the BCA method. Subsequently, $40 \mu \mathrm{g}$ of the extracted protein was added per lane and separated by SDS-PAGE on a $10 \%$ gel. Proteins were then transferred onto PVDF membranes and blocked with $5 \%$ non-fat milk in PBS with $0.1 \%$ Tween-20 at $4^{\circ} \mathrm{C}$ overnight. The membranes were then probed using the following primary antibodies: Osteopontin (OPN; cat. no. bs-0019P; 1:1,000; BIOSS), bone morphogenic protein 4
Table I. Sequences of each primer used in the present study.

\begin{tabular}{ll}
\hline Gene name & \multicolumn{1}{c}{ Primer pairs } \\
\hline Runx2 & F: 5'-TCTTAGAACAAATTCTGCCCTTT-3' \\
& R: 5'-TGCTTTGGTCTTGAAATCACA-3' \\
Osterix & F: 5'-AGAGATCTGAGCTGGGTAGAGG-3' \\
& R: 5'-AAGAGAGCCTGGCAAGAGG-3' \\
BMP4 & F: 5'-CTCCAAGAATGGAGGCTGTAGGAA-3' \\
& R: 5'-CCTATGAGATGGAGCAGGCAAGA-3' \\
OPN & F: 5'-ATCTCCTAGCCCCACAGAAT-3' \\
& R: 5'-CATCAGACTGGTGAGAATCATC-3' \\
TGF- $\beta 1$ & F: 5'-CTGCTGACCCCCACTGATAC-3' \\
& R: 5'-AGCCCTGTATTCCGTCTCCT-3' \\
TGF- $\beta$ RI & F: 5'-AAGATGACCGCT CTGACATCA-3' \\
& R: 5'-CTTATAGACCTCAGCAAAGCGAC-3' \\
GAPDH & F: 5'-ATTTGGTCGTATTGGGCG-3' \\
& R: 5'-TGGAAGATGGTGATGGGATT-3'
\end{tabular}

Runx2, runt-related transcription factor 2; BMP4, bone morphogenetic protein 4; OPN, osteopontin; RI, Receptor I; F, forward; R, reverse.

(BMP4; cat. no. GP20102; 1:1,000; GlpBio Technology), runt-related transcription factor 2 (Runx2; cat. no. ab114133; 1:2,000; Abcam), Osterix (cat. no. ab209484; 1:2,000; Abcam), TGF- $\beta 1$ (cat. no. E1A0340C; 1:1,000; EnoGene Biotech Co., Ltd.), TGF- $\beta$ Receptor I (RI; cat. no. E1A1126B-2; 1:1,000; EnoGene Biotech Co., Ltd.), Smad3 (cat. no. E1A0031B; 1:1,000; EnoGene Biotech Co., Ltd.), phosphorylated (p-) Smad3 (cat. no. E8ET1609-41; 1:1,000; EnoGene Biotech Co., Ltd.) and internal reference GAPDH (cat. no. ab8245; 1:20,000; Abcam) at room temperature for $2 \mathrm{~h}$. Subsequently, the blot was incubated with the diluted secondary antibody (1:5,000; cat. no. ab205718; Abcam) and labelled with HRP at room temperature for $1 \mathrm{~h}$, followed by a wash step with $0.1 \%$ TBST. Protein expression was detected using a SuperSignal ${ }^{\mathrm{TM}}$ West Femto Maximum Sensitivity Substrate kit (Roche Applied Science). The relative value of the target protein was calculated by comparing with the corresponding internal reference. Densitometry was conducted using the ImageJ software (v1.8.0; National Institutes of Health).

Statistical analysis. SPSS 21.0 software (IBM Corp.) was used for statistical analysis. Metrological data was first evaluated for normal distribution and data conforming to a normal distribution were expressed as mean \pm standard deviation. Mixed design ANOVA with Bonferroni post hoc test was used to compare differences between groups with multiple factors. One-way ANOVA with Tukey's post hoc test was used to compare differences among groups with a single factor. $\mathrm{P}<0.05$ was considered to indicate a statistically significant difference.

\section{Results}

Effect of psoralen on cell proliferation and viability. Results from the CCK- 8 assay demonstrated that elevated cell proliferation was exhibited by hBMSCs treated with psoralen 

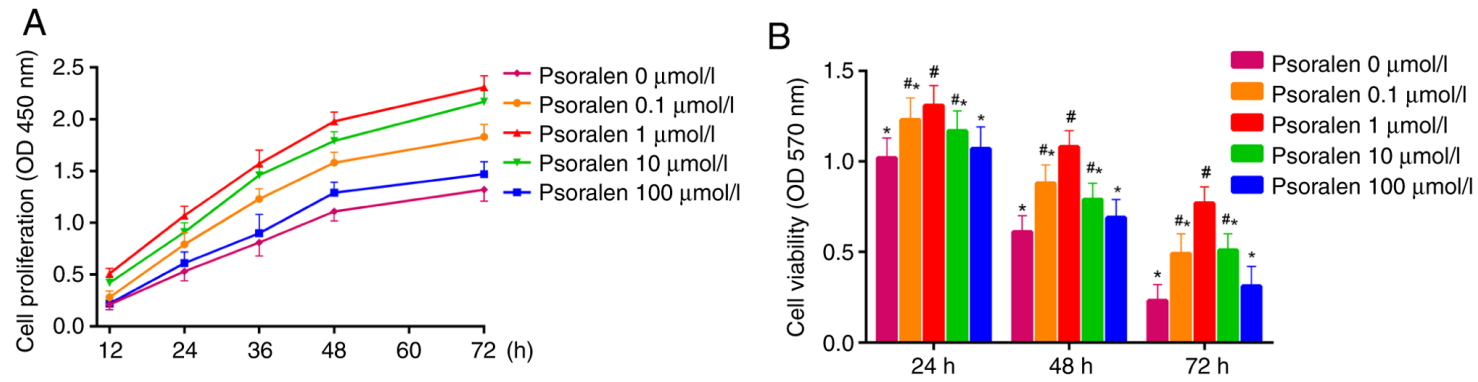

Figure 1. Effect of psoralen on cell activity. (A) Cell Counting Kit-8 assay demonstrated elevated cell viability in hBMSCs treated with psoralen at concentrations of $0.1,1$ and $10 \mu \mathrm{mol} / 1$. (B) MTT assay revealed that with no psoralen treatment ( $0 \mu \mathrm{mol} / 1$ group), the cell viability of hBMSCs gradually decreased after 24,48 and $72 \mathrm{~h}$. In contrast, low concentrations of psoralen $(0.1,1$ and $10 \mu \mathrm{mol} / \mathrm{l})$ maintained the viability of hBMSCs following treatment for 24,48 and $72 \mathrm{~h}$. ${ }^{\text {"P}} \mathrm{P}<0.05$ vs. $0 \mu \mathrm{mol} / 1$ group. ${ }^{*} \mathrm{P}<0.05 \mathrm{vs.} 1 \mu \mathrm{mol} / 1$ group. hBMSC, human bone marrow mesenchymal stem cells; OD, optical density.

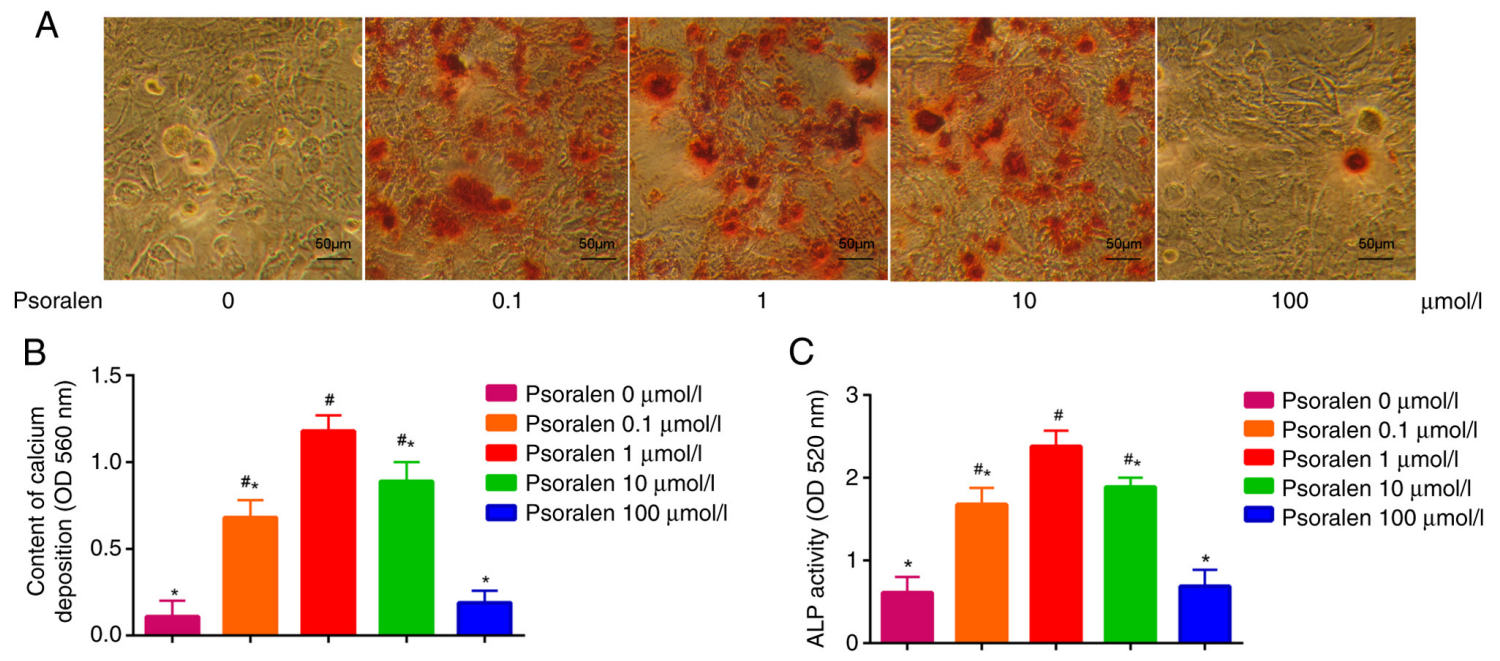

Figure 2. Effect of psoralen on the osteogenic differentiation of hBMSCs. (A) AR-S revealed that low concentrations (0.1, 1 and $10 \mu \mathrm{mol} / \mathrm{l})$ of psoralen can markedly promote the formation of calcium nodules in hBMSCs (magnification, x100). (B) Comparison of calcium deposition in different groups. (C) ALP activity was significantly enhanced by psoralen at low concentrations $(0.1,1$ and $10 \mu \mathrm{mol} / 1)$. ${ }^{\#} \mathrm{P}<0.05 \mathrm{vs} .0 \mu \mathrm{mol} / 1$ group. ${ }^{*} \mathrm{P}<0.05 \mathrm{vs} .1 \mu \mathrm{mol} / 1$ group. hBMSC, human bone marrow mesenchymal stem cells; ALP, alkaline phosphatase; AR-S, alizarin red S; OD, optical density.

at concentrations of $0.1,1$ and $10 \mu \mathrm{mol} / 1$, with $1 \mu \mathrm{mol} / 1$ demonstrating the highest elevation in proliferative activity compared with that in the NC group. There was no significant difference in cell proliferation between concentrations of 0 and $100 \mu \mathrm{mol} / 1$, although cell proliferation was higher at $100 \mu \mathrm{mol} / 1$ (Fig. 1A). MTT assay revealed that at 24,48 and $72 \mathrm{~h}$ after treatment with psoralen, cell viability of hBMSCs were increased at concentrations of $0.1,1$ and $10 \mu \mathrm{mol} / 1$ compared with that in the $\mathrm{NC}$ group (Fig. 1B). The optimal concentration was found to be $1 \mu \mathrm{mol} / 1$. Similarly, there was no significant difference in cell viability between 0 and $100 \mu \mathrm{mol} / 1$. (Fig. 1B).

Effect of psoralen on the osteogenic differentiation of hBMSCs. The effects of different concentrations of psoralen on the osteogenic differentiation of hBMSCs were evaluated by measuring ALP activity and AR-S staining of calcium deposition. The results demonstrated that low concentrations of psoralen $(0.1,1$ and $10 \mu \mathrm{mol} / \mathrm{l})$ significantly promoted the formation of calcified nodules and enhanced ALP activity in hBMSCs compared with those in the NC cell group. However, there was no significant difference in these two parameters tested between the high concentration $(100 \mu \mathrm{mol} / \mathrm{l})$ and NC groups $(0 \mu \mathrm{mol} / \mathrm{l})$. The most potent effect on the osteogenic differentiation of hBMSCs was found at $1 \mu \mathrm{mol} / 1$ psoralen (Fig. 2).

Effects of psoralen on the expression of genes associated with osteogenic differentiation and the TGF- $\beta / S m a d 3$ pathway of hBMSCs. The results of qPCR and western blot analysis revealed that low concentrations of psoralen promoted the expression of genes associated with osteogenic differentiation. Among these, at concentrations of $0.1,1$ and $10 \mu \mathrm{mol} / 1$, psoralen significantly promoted the expression of Osterix and BMP4 compared with those in the $0 \mu \mathrm{mol} / 1 \mathrm{NC}$ group, whilst at concentrations of 1,10 and $100 \mu \mathrm{mol} / 1$, psoralen significantly promoted the expression of OPN compared with those in the $0 \mu \mathrm{mol} / 1 \mathrm{NC}$ group. In terms of Runx2, only 0.1 and $1 \mu \mathrm{mol} / 1$ of psoralen significantly promoted expression of Runx 2 compared with that in the $0 \mu \mathrm{mol} / 1 \mathrm{NC}$ group (Fig. 3A and B). In all experimental conditions, $1 \mu \mathrm{mol} / 1$ was the optimal concentration. In addition, low concentrations of psoralen ( 1 and $10 \mu \mathrm{mol} / \mathrm{l})$ promoted the expression of TGF- $\beta 1$ and TGF- $\beta$ RI (Fig. $3 \mathrm{C}$ and D), whilst all concentrations of psoralen $(0.1,1,10$ and $100 \mu \mathrm{mol} / \mathrm{l})$ promoted the levels of p-Smad3 when compared with those in the $0 \mu \mathrm{mol} / 1 \mathrm{NC}$ group (Fig. 3C). In addition, the p-Smad3/Smad3 ratio was 
A

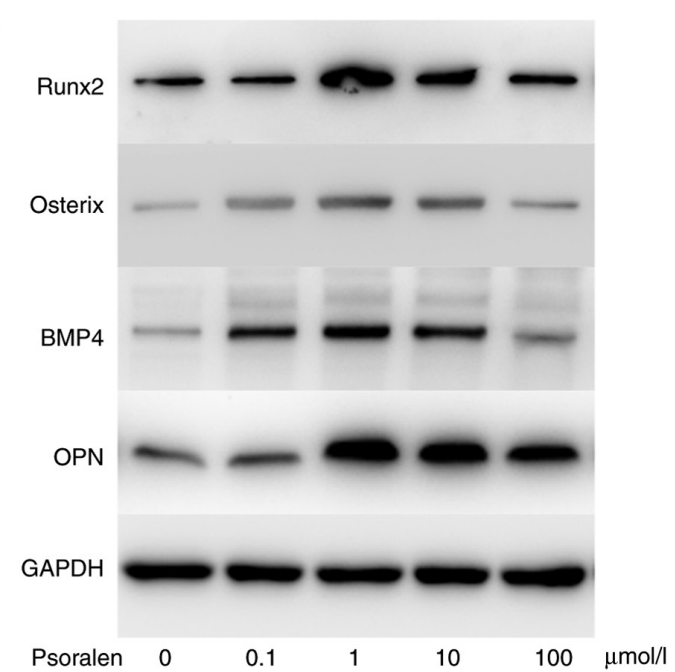

C

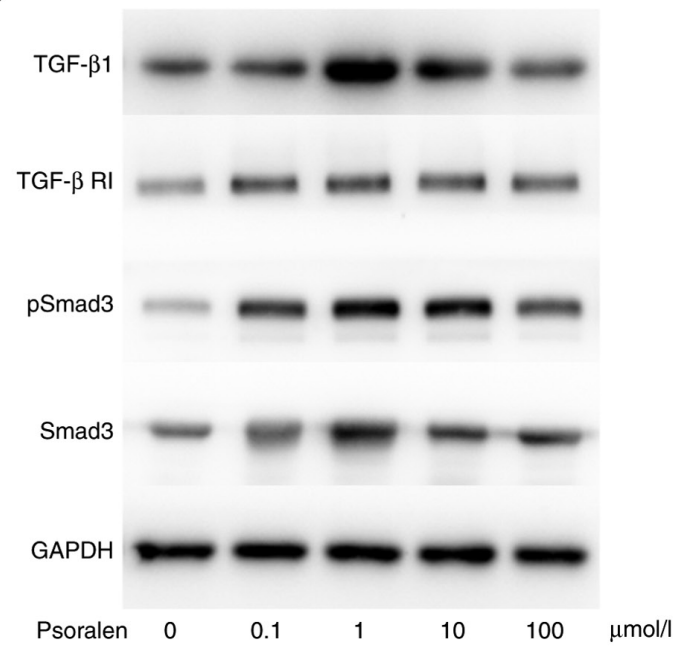

$\mathrm{B}$
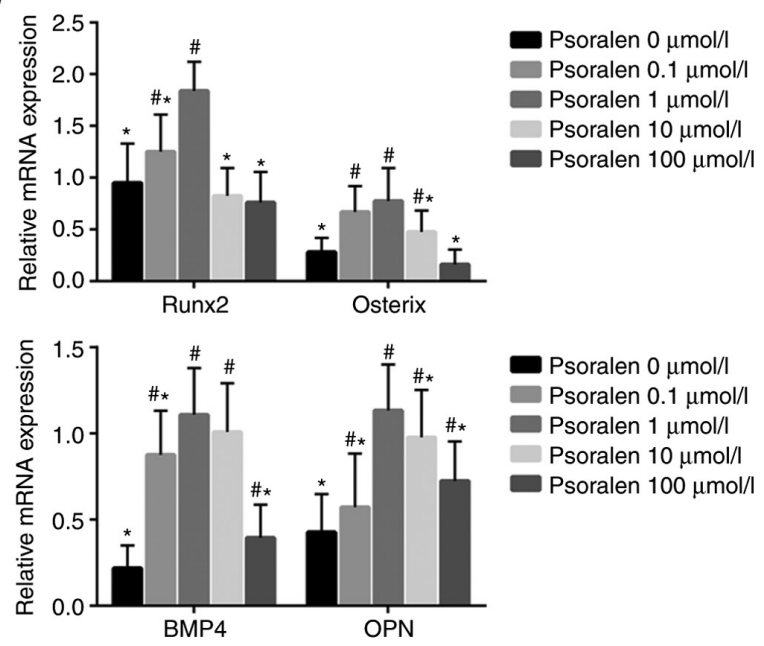

D

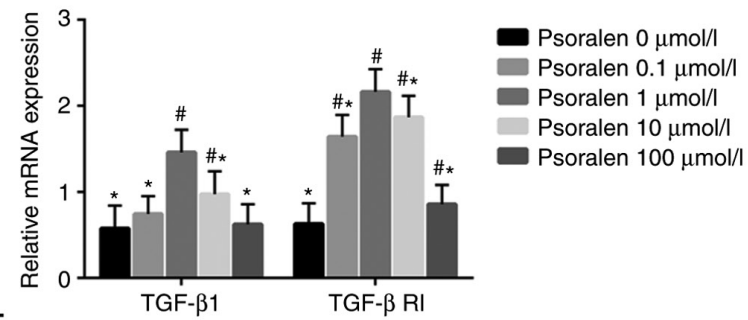

E

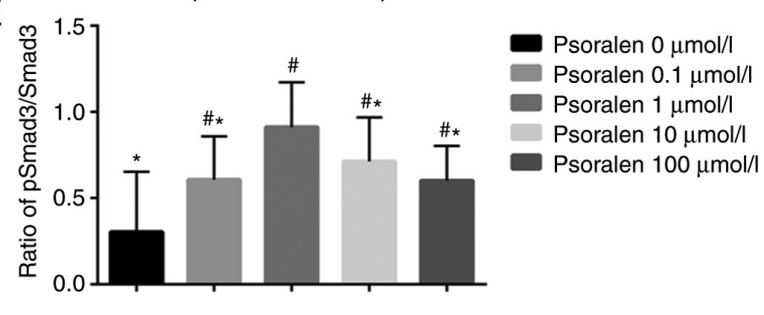

Figure 3. Effect of psoralen on the expression of genes associated with osteogenic differentiation and the TGF- $\beta / \mathrm{Smad} 3$ pathway of hBMSCs. Osteogenic differentiation-related gene and protein expression analysis using (A) western blotting and (B) RT-qPCR. (C) TGF- $\beta /$ Smad3 pathway activity and expression analysis using western blotting. (D) The expression of TGF- $\beta 1$ and TGF- $\beta$ RI using RT-qPCR. (E) Comparison of the p-Smad3/Smad3 ratio. "P<0.05 vs. $0 \mu \mathrm{mol} / 1$ group. ${ }^{*} \mathrm{P}<0.05$ vs. $1 \mu \mathrm{mol} / 1$ group. hBMSC, human bone marrow mesenchymal stem cells; RT-qPCR, reverse transcription-quantitative PCR; RI, Receptor I; p-, phosphorylated; Runx2, runt-related transcription factor 2; BMP4, bone morphogenetic protein 4; OPN, osteopontin.

significantly increased after treatment with psoralen compared with that in the $0 \mu \mathrm{mol} / 1$ group, with $1 \mu \mathrm{mol} / 1$ resulting in the largest increase (Fig. 3E).

Effect of the TGF- $\beta$ RI inhibitor SB431542 on osteogenic differentiation of hBMSCs. As indicated by the aforementioned results, $1 \mu \mathrm{mol} / 1$ psoralen demonstrated the optimal effect on the osteogenic differentiation of hBMSCs and the components of the TGF- $\beta / \mathrm{Smad} 3$ pathway. Therefore, $1 \mu \mathrm{mol} / 1$ psoralen was selected for subsequent experiments. AR-S results revealed that psoralen promoted calcium deposition in hBMSCs compared with all the other groups. By contrast, SB431542 significantly inhibited the calcium deposition of hBMSCs compared with the control group, whilst psoralen markedly reversed this inhibitory effect (Fig. 4A and B). There was no statistically significant difference between the control group and the psoralen + SB431542 group.

Effect of SB431542 on the expression of osteogenic differentiation-related genes. The results of the western blot analysis and RT-qPCR revealed that SB431542 significantly inhibited the expression of osteogenic differentiation-related genes compared with the control group, whilst psoralen effectively reversed the inhibitory effect of SB431542 on the osteogenic differentiation of hBMSCs (Fig. 5A and B). There was no statistically significant difference between those in the NC and the psoralen + SB431542 group. This suggest that the mechanism underlying psoralen treatment in the promotion of osteogenic differentiation in hBMSCs is closely associated with the TGF- $\beta / \mathrm{Smad} 3$ pathway.

\section{Discussion}

Previous studies have revealed that psoralen has a relaxant effect on smooth muscle, in addition to possessing the ability to stimulate bone formation and induce osteoblast differentiation without affecting cell proliferation $(12,13,15)$. BMSCs are abundant in bone tissues and have the potential for multidirectional differentiation $(4,5,16)$. In certain conditions, BMSCs can differentiate into osteoblasts with the increased 

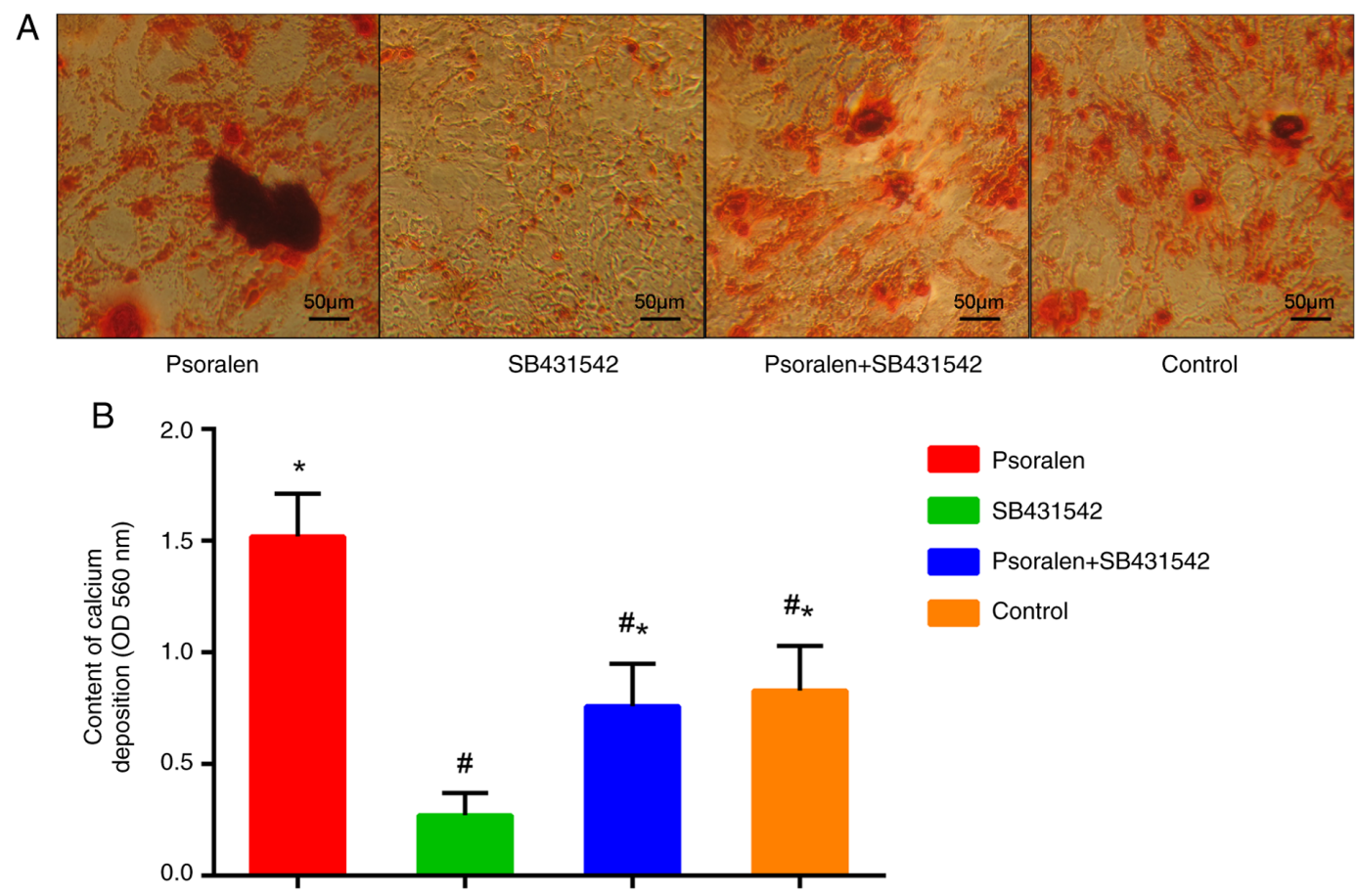

Figure 4. Effect of SB431542 on the osteogenic differentiation of human bone marrow mesenchymal stem cells. (A) Alizarin red S staining revealed formation of calcified nodules in the different groups (magnification, $\mathrm{x} 100$ ). (B) Comparison of calcium deposition among the different groups. "\#P<0.05 vs. psoralen group. ${ }^{*} \mathrm{P}<0.05$ vs. SB431542 group. OD, optical density; NS, not significant.

A

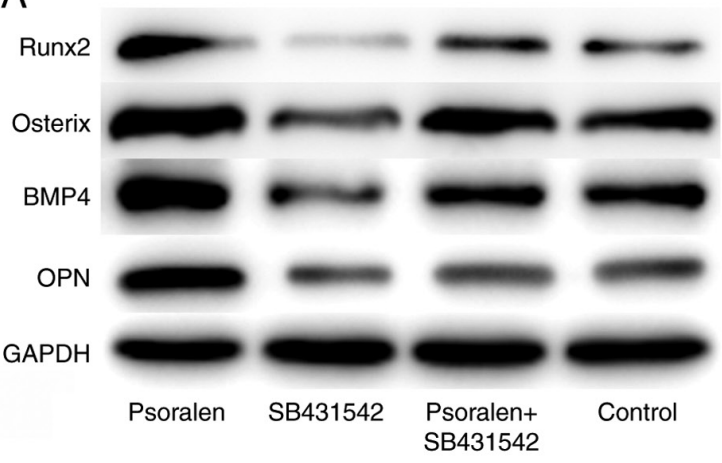

B

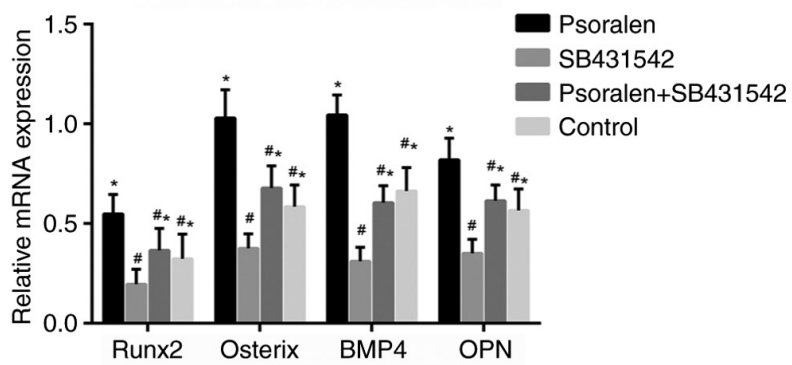

Figure 5. Effect of SB431542 on the expression of osteogenic differentiation-related genes in human bone marrow mesenchymal stem cells. (A) The expression of BMP4, OPN, Runx2 and Osterix in hBMSCs was measured using western blot analysis. (B) The results of reverse transcription-quantitative PCR were consistent with the western blot analysis. ${ }^{\text {P }}<0.05$ vs. psoralen group. ${ }^{*} \mathrm{P}<0.05$ vs. SB431542 group. BMP4, bone morphogenetic protein 4 ; OPN, osteopontin; Runx2, runt-related transcription factor 2; NS, not significant.

expression of osteogenic genes, including Runx2, Osterix and ALP $(17,18)$. In addition, alleviation of osteoporosis and the regeneration of osteoblasts have been previously shown to be closely associated with the number of BMSCs in the bone marrow and their osteogenic differentiation ability (4-6,19).

In a previous study, psoralen was revealed to promote the osteogenic differentiation of BMSCs via the miR-488/Runx2 pathway (11), however, the underlying molecular mechanism and signal pathway remained to be fully verified. In the present study, CCK-8 and MTT assays were used to measure cell viability and cell proliferation. These results demonstrated that psoralen promotes the proliferation of hBMSCs and maintains cell viability in a concentration-dependent manner. However, at the highest concentration tested $(100 \mu \mathrm{mol} / \mathrm{l})$, the result was not statistically significant when compared with $0.1 \mu \mathrm{mol} / 1$, with the overall optimal concentration demonstrated to be $1 \mu \mathrm{mol} / 1$.

ALP is an important marker of the osteogenic activity of hBMSCs and is a non-specific phosphomonoesterase that is used to determine the early osteogenic differentiation ability of hBMSCs (20). In addition, ALP serves an important role in hBMSC calcium deposition (21). AR-S is a method that is commonly used for examining hBMSC calcium deposition and for determining differentiation into advanced osteoblasts (22). Results from the present study revealed that low concentrations of psoralen, particularly at $1 \mu \mathrm{mol} / 1$, possessed the ability to potently promote ALP activity and calcified nodule formation in hBMSCs, suggesting that psoralen effectively promotes the osteogenic differentiation of hBMSCs. Huang et al (23) demonstrated that combination therapy with BMP-2 and 


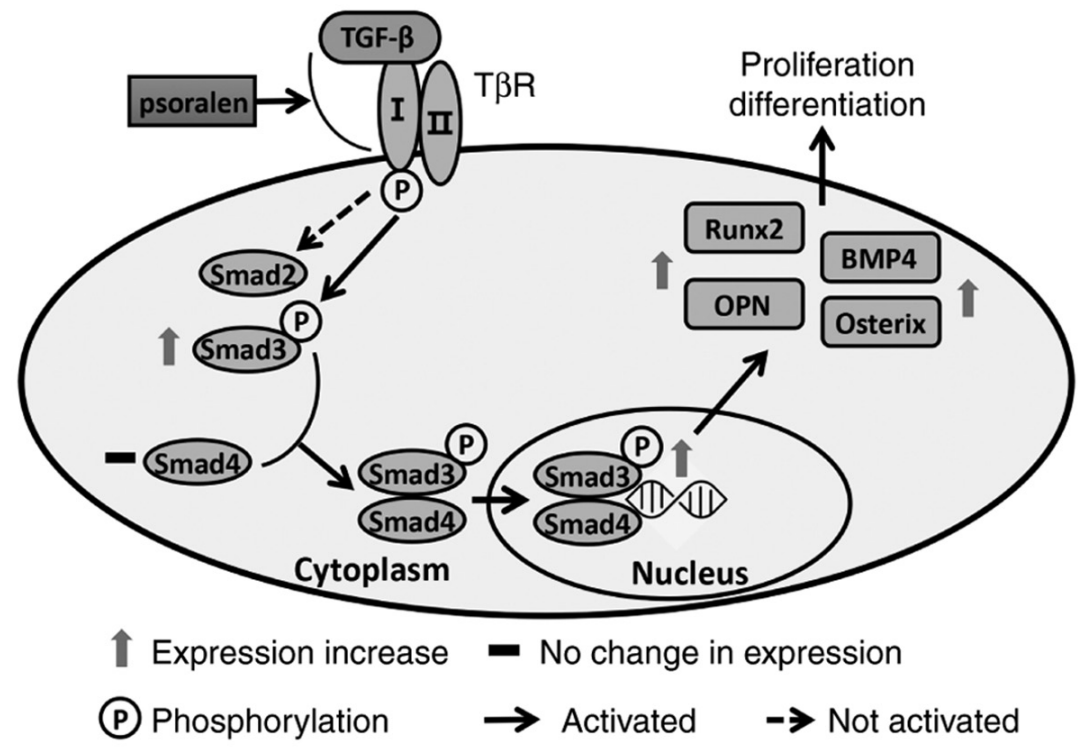

Figure 6. Proposed model of psoralen-induced osteogenic proliferation and differentiation through the TGF- $\beta /$ Smad 3 pathway in human bone marrow mesenchymal stem cells. BMP4, bone morphogenetic protein 4; OPN, osteopontin; Runx2, runt-related transcription factor 2; T $\beta$ R, TGF- $\beta$ receptor; p, phosphorylated.

psoralen enhanced fracture healing in ovariectomized mice through increased bone-specific ALP levels and decreased C-terminal telopeptide of type-1 collagen (23). Since hBMSCs are a type of adult stem cell with the potential for self-renewal and multi-directional differentiation $(24,25)$, it is hypothesised that specific concentrations of psoralen can result in the following: i) Effective promotion of the differentiation of hBMSCs into osteoblasts; ii) an increase the activity of ALP; and iii) promotion of the formation of calcium mineralization nodules.

To explore the underlying mechanism of psoralen in promoting osteogenic differentiation of hBMSCs further, RT-qPCR and western blot analysis were performed to probe the expression of genes associated with osteogenic differentiation, namely BMP4, OPN, Runx2 and Osterix. BMP4 belongs to the TGF- $\beta$ family that has been reported to induce cartilage and bone formation and regulates mesoderm induction, tooth development, limb formation and bone fracture repair (26). OPN is also known as secreted phosphoprotein 1 , bone sialoprotein 1 and nephropontin (27). OPN binds tightly to hydroxyapatite and appears to form an integral part of the mineralized matrix, which is important for cell-matrix interactions (27). Runx 2 is a specific transcription factor that is expressed in osteoblasts and is closely associated with the early proliferation of osteoblasts (28). Osterix is another key transcription factor, which is located downstream of Runx2 (29). Nakashima et al (29) demonstrated that the expression of osterix could not be detected in mice carrying a mutated version of Runx2; while the expression of Runx2 could be detected in osterix knockout mice (29). Subsequently, Nishio et al (30) further demonstrated that osterix was located downstream of the Runx 2 gene in mesenchymal cells (30). It was revealed that overexpression of Runx 2 significantly increased the promoter activity of osterix. This up-regulation was abrogated when the Runx 2 responsive element on the osterix promoter was mutated. It is only expressed in the bone tissue and plays a key role in the late differentiation and maturation of osteoblasts (31). In the present study, low-dose psoralen $(1 \mu \mathrm{mol} / \mathrm{l})$ effectively increased the expression of hBMSC osteogenic markers BMP4, OPN, Runx2 and Osterix. Therefore, specific concentrations of psoralen can activate the differentiation of hBMSCs into osteoblasts.

Signal transduction by the TGF- $\beta$ superfamily of proteins serves an important role in the regulation of cell proliferation, differentiation and development in many biological systems (32). Signal transduction starts with the ligand-induced oligomerization of serine/threonine receptor kinases and the phosphorylation of cytoplasmic signal transduction molecules Smad2 and Smad3 (33). The carboxyl terminus of Smad proteins is phosphorylated by an activated receptor, causing it to bind to the common signal transduction factor Smad4 and transporting it into the nucleus (34). Activated Smad proteins regulate various biological processes by binding to transcription factors, such as BMP, leading to the transcriptional regulation of cell states (35). Once bound to the corresponding receptors, transforming growth factors, activin, TGF- $\beta$ and BMP will cause Smad to be phosphorylated, thereby activating the TGF- $\beta /$ Smad signalling pathway (36). In the present study, psoralen $(1 \mu \mathrm{mol} / \mathrm{l})$ significantly promoted the activation of the TGF- $\beta /$ Smad3 signalling pathway and mediated the strongest effect on the promotion of osteoblast differentiation. It was therefore hypothesised that psoralen promotes the binding of TGF- $\beta$ to the TGF- $\beta$ RI, which subsequently stimulates RI-mediated Smad3 signaling. Thus, Smad3 is activated in the nucleus which mediates the transcription of specific genes and induces the differentiation of hBMSCs into osteoblasts (Fig. 6). This then strengthens the activity of osteoblasts and promotes the mineralization of the extracellular matrix.

To test this hypothesis, $5 \mathrm{~mol} / 1$ TGF- $\beta$ RI inhibitor SB431542 (37) was applied to the hBMSCs. The results of the present study demonstrated that SB431542 effectively inhibited the formation of calcified nodules in hBMSCs and 
the expression of genes associated with osteogenic differentiation. Furthermore, psoralen reversed the inhibitory effect of SB431542 on the osteogenic differentiation of hBMSCs. This further suggests that psoralen can promote the differentiation of hBMSCs into osteoblasts by activating the TGF- $\beta / \mathrm{Smad} 3$ pathway. Combining this with findings from previous studies (11), this indicate that psoralen regulates the expression of Runx 2 through the TGF- $\beta / \mathrm{Smad} 3$ pathway, thereby regulating the osteogenic differentiation of BMSCs.

In conclusion, the present study suggest that psoralen promotes hBMSC cell proliferation, maintain cell viability and increase the expression of genes associated with osteogenic differentiation in hBMSCs, which may be closely associated with the activation of the TGF- $\beta /$ Smad 3 pathway. However, the present study has some limitations, such as the blocking of TGF- $\beta$ RI alone and not the Smad pathway, which may lead to insufficient results. A combination of blocking both TGF- $\beta$ RI and Smad would more accurately prove that psoralen promotes the differentiation of hBMSCs into osteoblasts through the TGF- $\beta /$ Smad 3 pathway. In addition, it remains unclear how psoralen activates the binding of TGF- $\beta$ to the receptor, therefore the precise molecular mechanism underlying this phenomenon remains to be fully elucidated and is therefore a matter for future research.

\section{Acknowledgements}

Not applicable.

\section{Funding}

The present study was supported by the National Natural Science Foundation (grant nos. 82004387 and 81804047) and Natural Science Foundation of Guangdong Province (grant no. 2018A030313694).

\section{Availability of data and materials}

The datasets used and/or analyzed during the current study are available from the corresponding author on reasonable request.

\section{Authors' contributions}

QH, YH and JL conceived and designed the experiments; YH, LL and TJ performed the experiments; HS and XC contributed to the statistical analysis of the data. $\mathrm{YH}$ and $\mathrm{QH}$ confirm the authenticity of all the raw data. All authors have read and approved the final manuscript.

\section{Ethics approval and consent to participate}

Not applicable.

\section{Patient consent for publication}

Not applicable.

\section{Competing interests}

The authors declare that they have no competing interests.

\section{References}

1. Xie Y, Wang J, Wang L, Zhu Y, Lei L, Wan T, Liao X, Liang B, Pang G, Miyamoto A, et al: Research trends in osteoporosis in Asian countries and regions in the last 20 years. Arch Osteoporos 15: 130, 2020.

2. Föger-Samwald U, Dovjak P, Azizi-Semrad U, Kerschan-Schindl K and Pietschmann P: Osteoporosis: Pathophysiology and therapeutic options. EXCLI J 19: 1017-1037, 2020.

3. Kim Y, Tian Y, Yang J, Huser V, Jin P, Lambert CG, Park H, You SC, Park RW, Rijnbeek PR, et al: Comparative safety and effectiveness of alendronate versus raloxifene in women with osteoporosis. Sci Rep 10: 11115, 2020.

4. Liu Y, Wang H, Dou H, Tian B, Li L, Jin L, Zhang Z and Hu L: Bone regeneration capacities of alveolar bone mesenchymal stem cells sheet in rabbit calvarial bone defect. J Tissue Eng 11: 2041731420930379, 2020.

5. Dong R, Bai Y, Dai J, Deng M, Zhao C, Tian Z, Zeng F, Liang W, Liu L and Dong S: Engineered scaffolds based on mesenchymal stem cells/preosteoclasts extracellular matrix promote bone regeneration. J Tissue Eng 11: 2041731420926918, 2020.

6. Safarova Y, Umbayev B, Hortelano $G$ and Askarova S: Mesenchymal stem cells modifications for enhanced bone targeting and bone regeneration. Regen Med 15: 1579-1594, 2020.

7. Chow L, Johnson V, Regan D, Wheat W, Webb S, Koch P and Dow S: Safety and immune regulatory properties of canine induced pluripotent stem cell-derived mesenchymal stem cells. Stem Cell Res (Amst) 25: 221-232, 2017.

8. King NM and Perrin J: Ethical issues in stem cell research and therapy. Stem Cell Res Ther 5: 85, 2014.

9. Yang Z, Huang JH, Liu SF,Zhao YJ, ShenZY, Wang YJ and Bian Q: The osteoprotective effect of psoralen in ovariectomy-induced osteoporotic rats via stimulating the osteoblastic differentiation from bone mesenchymal stem cells. Menopause 19: 1156-1164, 2012.

10. Yuan X, Bi Y, Yan Z, Pu W, Li Y and Zhou K: Psoralen and Isopsoralen Ameliorate Sex Hormone Deficiency-Induced Osteoporosis in Female and Male Mice. BioMed Res Int 2016: 6869452, 2016.

11. Huang Y, Hou Q, Su H, Chen D, Luo Y and Jiang T: miR-488 negatively regulates osteogenic differentiation of bone marrow mesenchymal stem cells induced by psoralen by targeting Runx 2 . Mol Med Rep 20: 3746-3754, 2019.

12. Li F, Li Q, Huang X, Wang Y, Ge C, Qi Y, Guo W and Sun H: Psoralen stimulates osteoblast proliferation through the activation of nuclear factor- $\kappa \mathrm{B}$-mitogen-activated protein kinase signaling. Exp Ther Med 14: 2385-2391, 2017.

13. Tang DZ, Yang F, Yang Z, Huang J, Shi Q, Chen D and Wang YJ: Psoralen stimulates osteoblast differentiation through activation of BMP signaling. Biochem Biophys Res Commun 405: 256-261, 2011.

14. Livak KJ and Schmittgen TD: Analysis of relative gene expression data using real-time quantitative PCR and the 2(-Delta Delta C(T)) method. Methods 25: 402-408, 2001.

15. Wong RW and Rabie AB: Effect of psoralen on bone formation. J Orthop Res 29: 158-164, 2011.

16. Wang Z, Shi Y, Chen W, Wei H and Shang J: Mesenchymal stem cells repair bone marrow damage of aging rats and regulate autophagy and aging genes. Cell Biochem Funct 38: 792-800, 2020.

17. Xu C, Liu H, He Y, Li Y and He X: Endothelial progenitor cells promote osteogenic differentiation in co-cultured with mesenchymal stem cells via the MAPK-dependent pathway. Stem Cell Res Ther 11: 537, 2020.

18. Zhang S, Sun S, He J and Shen L: NT-3 promotes osteogenic differentiation of mouse bone marrow mesenchymal stem cells by regulating the Akt pathway. J Musculoskelet Neuronal Interact 20: 591-599, 2020.

19. Wu Y, Tang Y, Zhang X, Chu Z, Liu Y and Tang C: MMP-1 promotes osteogenic differentiation of human bone marrow mesenchymal stem cells via the JNK and ERK pathway. Int J Biochem Cell Biol 129: 105880, 2020.

20. O'Grady S and Morgan MP: Deposition of calcium in an in vitro model of human breast tumour calcification reveals functional role for ALP activity, altered expression of osteogenic genes and dysregulation of the TRPM7 ion channel. Sci Rep 9: 542, 2019. 
21. Zhang J, Zhang W, Dai J, Wang X and Shen SG: Overexpression of Dlx2 enhances osteogenic differentiation of BMSCs and MC3T3-E1 cells via direct upregulation of Osteocalcin and Alp. Int J Oral Sci 11: 12, 2019.

22. Li J, Wang X, Yang F, Yuan J, Cui Q, Nie F and Zhang J: Matrine enhances osteogenic differentiation of bone marrow-derived mesenchymal stem cells and promotes bone regeneration in rapid maxillary expansion. Arch Oral Biol 118: 104862, 2020.

23. Huang K, Wu G, Zou J and Peng S: Combination therapy with BMP-2 and psoralen enhances fracture healing in ovariectomized mice. Exp Ther Med 16: 1655-1662, 2018.

24. Tuan RS, Boland G and Tuli R: Adult mesenchymal stem cells and cell-based tissue engineering. Arthritis Res Ther 5: 32-45, 2003.

25. Pereira RF, Halford KW, O'Hara MD, Leeper DB, Sokolov BP, Pollard MD, Bagasra O and Prockop DJ: Cultured adherent cells from marrow can serve as long-lasting precursor cells for bone, cartilage, and lung in irradiated mice. Proc Natl Acad Sci USA 92: 4857-4861, 1995.

26. Choi J, Bae T, Byambasuren N, Park SH, Jo CH, Kim D, Hur JK and Hwang NS: CRISPR-Cpf 1 activation of endogenous BMP4 gene for osteogenic differentiation of umbilical-cord-derived mesenchymal stem cells. Mol Ther Methods Clin Dev 17: 309-316, 2020

27. Carvalho MS, Cabral JM, da Silva CL and Vashishth D: Synergistic effect of extracellularly supplemented osteopontin and osteocalcin on stem cell proliferation, osteogenic differentiation, and angiogenic properties. J Cell Biochem 120: $6555-6569,2019$

28. Narayanan A, Srinaath N, Rohini M and Selvamurugan N: Regulation of Runx 2 by MicroRNAs in osteoblast differentiation. Life Sci 232: 116676, 2019.
29. Nakashima K,Zhou X,KunkelG,Zhang Z, Deng JM,BehringerRR and de Crombrugghe $\mathrm{B}$ : The novel zinc finger-containing transcription factor osterix is required for osteoblast differentiation and bone formation. Cell 108: 17-29, 2002.

30. Nishio Y, Dong Y,Paris M, O'Keefe RJ, Schwarz EM and Drissi H: Runx2-mediated regulation of the zinc finger Osterix/Sp7 gene. Gene 372: 62-70, 2006.

31. Fu X, Li Y, Huang T, Yu Z, Ma K, Yang M, Liu Q, Pan H, Wang H, Wang J, et al: Runx2/Osterix and Zinc Uptake Synergize to Orchestrate Osteogenic Differentiation and Citrate Containing Bone Apatite Formation. Adv Sci (Weinh) 5: 1700755, 2018.

32. Thatcher JD: The TGF-beta signal transduction pathway. Sci Signal 3: tr4, 2010

33. Frick CL, Yarka C, Nunns $H$ and Goentoro L: Sensing relative signal in the Tgf- $\beta /$ Smad pathway. Proc Natl Acad Sci USA 114: E2975-E2982, 2017.

34. Si J, Yang B, Yu J, Li Y and Gao P: Effect of MiR-21 on pulmonary arterial hypertension via the TGF- $\beta 1 / \mathrm{Smad} 2$ signal pathway. Minerva Med 111: 181-183, 2020.

35. Xiao YT, Xiang LX and Shao JZ: Bone morphogenetic protein. Biochem Biophys Res Commun 362: 550-553, 2007.

36. Hudnall AM, Arthur JW and Lowery JW: Clinical relevance and mechanisms of antagonism between the BMP and activin/TGF- $\beta$ signaling pathways. J Am Osteopath Assoc 116: 452-461, 2016.

37. Zhou HQ, Liu MS, Deng TB, Xie PB, Wang W, Shao T, Wu Y and Zhang P: The TGF- $\beta /$ Smad pathway inhibitor SB431542 enhances the antitumor effect of radiofrequency ablation on bladder cancer cells. OncoTargets Ther 12: 7809-7821, 2019.

(i) (\$) This work is licensed under a Creative Commons Attribution-NonCommercial-NoDerivatives 4.0 International (CC BY-NC-ND 4.0) License. 